\title{
Suplementação de fitase microbiana na dieta de alevinos de jundiá: efeito sobre o desempenho produtivo e as características de carcaça
}

\author{
Dietary microbial phytase supplementation of silver catfish fingerlings: effect of performance and \\ carcass characteristics
}

\author{
Cleber Bastos Rocha' Juvêncio Luís Osório Fernandes Pouey ${ }^{\mathrm{II}}{ }^{*}$ Dariane Beatriz Schoffen Enke $^{\mathrm{I}}$ \\ Eduardo Gonçalves Xavier ${ }^{\text {II }}$ Diones Bender AlmeidaII
}

\section{RESUMO}

Este estudo foi realizado para avaliar os efeitos da adição de diferentes níveis de fitase na dieta sobre o desempenho produtivo e as características de carcaça de alevinos de jundiá (Rhamdia quelen). Foram utilizados 208 alevinos com peso vivo inicial médio de $2,92 \pm 0,59 \mathrm{~g}$, distribuídos em um delineamento inteiramente casualizado com quatro tratamentos $\left(0,500,1.000\right.$ e $\left.1.500 F T U k^{-1}\right)$ e quatro repetições. $\mathrm{Na}$ composição das dietas, foram utilizados somente ingredientes de origem vegetal e o alimento foi fornecido duas vezes ao dia. A cada quinzena, foram avaliados os parâmetros produtivos $e$, ao término do período experimental (45 dias), foram ainda realizadas avaliações nas carcaças. O ganho de peso médio foi significativamente crescente $(P<0,05)$ entre os tratamentos sem adição de fitase ( $0 \mathrm{FTU} \mathrm{\textrm {kg } ^ { - 1 }}$ ) e o nível máximo utilizado (1500FTU $\mathrm{kg}^{-1}$ ) na dieta, variando de $1,24 \pm 0,27 \mathrm{~g}$ para $1,73 \pm 0,23 \mathrm{~g}$, respectivamente. A taxa de crescimento específico também teve efeito significativo $(P<0,05)$ nos tratamentos sem fitase e 1.500FTUkg-1, passando de $0,78 \pm 0,12 \%$ para $1,07 \pm 0,11 \%$. Entretanto, o extrato etéreo na carcaça foi linearmente decrescente com os níveis de fitase na dieta em todos os tratamentos $(P<0,05)$, reduzindo de $13,54 \pm 0,02 \%$ (sem fitase) para 10,59 $\pm 0,10 \%$ (1.500FTU $\left.\mathrm{kg}^{-1}\right)$. A inclusão de níveis crescentes de fitase na dieta, até $1.500 \mathrm{FTU} \mathrm{kg}^{-1}$, melhora o desempenho e as características de carcaça de alevinos de jundiá.

Palavras-chave: ácido fítico, fósforo, Rhamdia quelen.

\section{ABSTRACT}

This study evaluated the effects of adding increasing levels of microbial phytase to diets on performance and carcass traits of silver catfish fingerlings (Rhamdia quelen). Two-

\begin{abstract}
hundred and eight silver catfish fingerlings (average initial weight: $2.92 \pm 0.59 \mathrm{~g}$ ) were randomly allotted to 4 treatments (0,500, 1000 and 1500 phytase units $\mathrm{kg}^{-1}$ of diet) with 4 replications, in a completely randomized design. No animal protein was added to the diets. The experiment was conducted for 45 days and fish were fed twice daily. Effects of phytase on performance were measured each 15 days and carcass traits were evaluated at the end of trial. Increasing levels of phytase linearly improved weight gain, from $1.24 \pm 0.27 \mathrm{~g}$ (no phytase) to $1.73 \pm 0.23 \mathrm{~g}\left(1500 \mathrm{PU} \mathrm{kg}^{-1}\right.$ of diet) $(\mathrm{P}<0.05)$; and rate of specific growth, from $0.78 \pm 0.12 \%$ (no phytase) to $1.07 \pm 0.11 \%$ (1500PU kg-1 of diet) $(P<0.05)$. However, ether extract of carcass was linearly reduced, from $13.54 \pm 0.02 \%$ (no phytase) to $10.59 \pm 0.10 \%$ (1500PU $\mathrm{kg}^{-1}$ of diet) $(P<0.05)$. Increasing levels of dietary microbial phytase, up to $1500 \mathrm{PU} \mathrm{kg}^{-1}$ of diet, improve performance and carcass traits of silver catfish fingerlings.
\end{abstract}

Key words: phytic acid, phosphorus, Rhamdia quelen.

\section{INTRODUÇÃO}

A farinha de pescado contém altos níveis de proteína bruta com elevado valor biológico. A redução na oferta, a variabilidade na composição e o alto custo têm levado nutricionistas a procurarem fontes alternativas à demanda de rações para aqüicultura (PADUA et al., 2000). A utilização de ingredientes de origem vegetal na dieta de peixes é limitada devido à presença de vários fatores

IPrograma de Pós-graduação em Zootecnia, Universidade Federal de Pelotas (UFPel), Pelotas, RS, Brasil.

${ }^{I}$ Departamento de Zootecnia, UFPel, CP 354, 96001-970, Pelotas, RS, Brasil. E-mail: juvencio@ufpel.tche.br.*Autor para correspondência.

IIICurso de Agronomia, UFPel, Pelotas, RS, Brasil. 
antinutricionais. Entre estes estão os inibidores de proteases, o fitato, os antivitamínicos, o gossipol, o tanino e os compostos antigênicos (FRANCIS et al., 2001).

A maior parte do fósforo $(\mathrm{P})$ nos grãos de oleaginosas e nos cereais encontra-se combinada com o inositol, formando a molécula do ácido fítico ou hexafosfato de mioinositol, com grande potencial quelatizador de minerais catiônicos, proteínas e aminoácidos (CHENG \& HARDY, 2002; PIZZOLANTE et al., 2002; VIELMA et al., 2004; DEBNATH et al., 2005). $\mathrm{O}$ fitato presente nas sementes é indisponível para os não-ruminantes, devido à ausência da enzima fitase no trato gastrintestinal, sendo necessária a suplementação das rações com P inorgânico (VAN WEERD et al., 1999; SALES et al., 2003; SAJJADI \& CARTER, 2004).

A fitase (EC 3.1.3.8 e EC 3.1.3.26) degrada o ácido fítico e seus sais (fitatos) liberando inositol, inositol monofosfato e fosfato inorgânico (CASEY \& WALSH, 2004). O desperdício de $P$ causa preocupação na aqüicultura de água doce, porque este mineral geralmente é o fator mais limitante para crescimento de algas neste ambiente, sendo que seu excesso pode estimular eutrofização (OVERTURF et al., 2003).

O jundiá (Rhamdia quelen) é menos sensível às oscilações térmicas do outono-inverno do extremo sul do Rio Grande do Sul, apresentando melhor ganho de peso, maior ganho de biomassa e maior taxa de sobrevivência do que o catfish (Ictalurus punctatus). Na atualidade, as técnicas de reprodução do jundiá estão dominadas, faltando as determinações relacionadas à nutrição, aos sistemas de cultivo e ao melhoramento genético da espécie (SOUZA et al., 2005). Assim, o objetivo do presente experimento foi avaliar o efeito da suplementação de diferentes níveis de fitase na dieta sobre o desempenho produtivo e as características de carcaça de alevinos de jundiá.

\section{MATERIAL E MÉTODOS}

A pesquisa foi conduzida no Laboratório de Piscicultura do Departamento de Zootecnia da Faculdade de Agronomia Eliseu Maciel da Universidade Federal de Pelotas, no período de 21 de fevereiro a 06 de abril de 2005 ( 45 dias). Foram utilizados 208 alevinos de jundiá com peso vivo inicial médio de $2,92 \pm 0,59 \mathrm{~g}$, distribuídos em um delineamento inteiramente casualizado. Foram testados quatro níveis de suplementação de fitase na dieta $(0,500,1.000 \mathrm{e}$ $1.500 \mathrm{FTU} \mathrm{kg}{ }^{-1}$ de dieta) constituindo os tratamentos, com quatro repetições. Cada unidade experimental foi composta por um aquário com $30 \mathrm{~L}$ de água contendo uma pedra porosa acoplada a um soprador central e 13 peixes. As dietas experimentais foram isoenergéticas (3.200kcal ED/kg na MS) e isoprotéicas (35\% PB), tendo como base protéica o farelo de soja associado à levedura de cana (Tabela 1). A fitase foi dissolvida em água morna $\left(42^{\circ} \mathrm{C}\right)$ na proporção de $30 \%$ do peso seco da dieta, conforme FURUYA et al. (2001), e pulverizada sobre as dietas nos níveis de 0,500, 1.000 e 1.500FTU $\mathrm{kg}^{-1}$. A fitase utilizada no experimento foi da marca comercial Natuphos ${ }^{\circledR} 5000 \mathrm{G}$, obtida pela fermentação por meio de fungos do grupo Aspergillus niger, a qual contém, conforme o fabricante, atividade inicial mínima de 5.000FTU g ${ }^{-1}$. Após este processo, as dietas foram homogeneizadas separadamente em misturador em " $y$ ", peletizadas em "moinho de carne" e secadas a $50^{\circ} \mathrm{C}$, durante 18 horas, em estufa com circulação de ar. Após a secagem, as dietas foram trituradas em moinho, peneiradas para obtenção de partículas com diâmetro entre 2,38 e 1,00mm, embaladas em pequenas porções e armazenadas sob refrigeração $\left(4^{\circ} \mathrm{C}\right)$. As dietas foram analisadas para verificação da composição bromatológica (método de Weende) no Laboratório de Nutrição Animal do Departamento de Zootecnia da Faculdade de Agronomia Eliseu Maciel da Universidade Federal de Pelotas e a atividade enzimática no Laboratório de Análises Químicas da BASF S.A. - Guaratinguetá - SP (Tabela 1).

$\mathrm{O}$ alimento foi ministrado duas vezes ao dia (9 e 17 horas), na proporção de $10 \%$ da biomassa total. A salinidade da água foi aumentada adicionando-se $2 \%$ de sal grosso comum por litro de água, durante o período experimental, para manutenção do equilíbrio osmótico.

Diariamente, no período da manhã, eram efetuadas limpezas dos aquários, através de sifão, para retirada de fezes, restos de alimentos e troca de água (cerca de 30\% do volume de água contida no aquário), quando se verificava também os parâmetros físicoquímicos da água: oxigênio dissolvido e temperatura, $\mathrm{pH}$ e condutividade, através de oxímetro (YSI-55), phmetro (F-1002, Bernauer Aquicultura) e condutivímetro (F-1000, Bernauer Aquicultura).

A cada 15 dias, os animais eram submetidos a uma biometria individual (após jejum de 24 horas), que consistia na pesagem (balança digital $0,1 \mathrm{~g}$ ) e medição do comprimento padrão e total (régua milimetrada). Ao término do período experimental, 10 animais por tratamento foram anestesiados e sacrificados para determinação do rendimento de carcaça (peixe eviscerado e com cabeça).

A influência da fitase foi avaliada nas variáveis: peso final $(\mathrm{g})$; ganho de peso médio $(\mathrm{GP}(\mathrm{g})=$ peso final inicial), comprimento padrão $(\mathrm{cm})$, sobrevivência $(\mathrm{S}(\%)=$ 
Tabela 1 - Composição das dietas testadas no experimento para alevinos de jundiá.

\begin{tabular}{|c|c|c|c|c|}
\hline \multirow{2}{*}{ Ingredientes $(\%)$} & \multicolumn{4}{|c|}{ Fitase (FTU kg-1 de dieta) } \\
\hline & 0 & 500 & 1000 & 1500 \\
\hline Farelo de soja & 36,00 & 36,00 & 36,00 & 36,00 \\
\hline Levedura de cana & 36,00 & 36,00 & 36,00 & 36,00 \\
\hline Milho triturado & 9,00 & 8,99 & 8,98 & 8,97 \\
\hline Óleo de soja & 7,00 & 7,00 & 7,00 & 7,00 \\
\hline Farelo de trigo & 6,00 & 6,00 & 6,00 & 6,00 \\
\hline Premix vitamínico e mineral ${ }^{1}$ & 5,00 & 5,00 & 5,00 & 5,00 \\
\hline Sal comum iodado & 1,00 & 1,00 & 1,00 & 1,00 \\
\hline Natuphos ${ }^{\circledR} 5000 \mathrm{G}$ & 0,00 & 0,01 & 0,02 & 0,03 \\
\hline Total & 100,00 & 100,00 & 100,00 & 100,00 \\
\hline \multicolumn{5}{|c|}{ Composição bromatológica $^{2}$} \\
\hline Matéria seca (\%) & 87,98 & 86,91 & 86,03 & 91,04 \\
\hline Extrato etéreo (\%) & 10,85 & 10,71 & 9,43 & 10,06 \\
\hline Cinzas $(\%)$ & 6,50 & 6,29 & 6,31 & 6,53 \\
\hline Proteína bruta (\%) & 37,01 & 36,55 & 36,75 & 36,89 \\
\hline Energia digestível (calculada) $\left(\mathrm{kcal} \mathrm{kg}^{-1}\right)$ & 3200 & 3200 & 3200 & 3200 \\
\hline Atividade enzimática da fitase ${ }^{3}$ & 0,00 & 420,00 & 1147,00 & 1522,00 \\
\hline
\end{tabular}

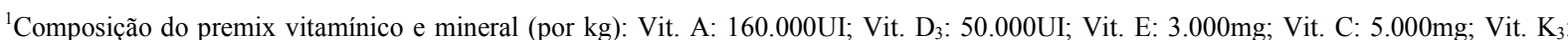
200mg; Riboflavina: 400mg; Ácido Pantotênico: 1.000mg; Niacina: 2.000mg; Vit. B 12 : 6.000mcg; Ácido Fólico: 120mg; Tiamina: 400mg; Piridoxina: 300mg; Cu: $12.001 \mathrm{mg}$; Fe: 1.200mg; Mn: 300mg; I: 10.000mg; Se: 2.000mg; Zn: 1.000mg; Ca: 6g; Co: 2.000; Colina: 85g; P: 2g; Lisina 30g; Mg: 1g; Na: 2,5g; Treonina: 25g.

${ }_{2}^{2}$ Análises bromatológicas realizadas no Laboratório de Nutrição Animal do Departamento de Zootecnia da Faculdade de Agronomia Eliseu Maciel da Universidade Federal de Pelotas - UFPel, Pelotas - RS.

${ }^{3}$ Atividade enzimática em (FTU kg ${ }^{-1}$ dieta) realizada no Laboratório de Análises Químicas da BASF S.A. - Guaratinguetá -SP.

[sobreviventes/população inicial] $\times 100)$, taxa de crescimento específico $(\mathrm{TCE}(\%)=[(\ln$ peso final $-\ln$ peso inicial)/dias de experimento] $\times 100$ ), fator de condição corporal $\left(\mathrm{FC}=\right.$ peso/comprimento total $\left.{ }^{3}\right)$ e rendimento de carcaça $(\mathrm{RC}(\%)=[$ peso peixe eviscerado/peso peixe inteiro] $\times 100$ ).

Para determinação da composição corporal, foram utilizados cinco animais por tratamento (carcaça com cabeça), sendo executada da seguinte forma: a umidade através da secagem em estufa a $105^{\circ} \mathrm{C}$ até peso constante. Após este processo, alíquotas dessas amostras destinaram-se às análises de extrato etéreo (extrator de Sohxlet), proteína bruta ( $\mathrm{N}$ x 6,25), pelo método Microkjeldahl, e cinzas (mufla a $550^{\circ} \mathrm{C}$ por 6 horas), de acordo com a AOAC (1990). Todas as análises foram realizadas em triplicata, no Laboratório de Nutrição Animal do Departamento de Zootecnia da Faculdade de Agronomia Eliseu Maciel da Universidade Federal de Pelotas. Os dados obtidos foram submetidos à análise de variância (ANOVA) e regressão polinomial, considerando-se as diferenças significativas ao nível de probabilidade de $5 \%$, utilizando-se o programa estatístico Statistica $^{\circledR} 5.0$ (StatSoft Inc., 1995).

\section{RESULTADOS E DISCUSSÃO}

Os valores médios observados para os parâmetros físico-químicos da água no período experimental foram: oxigênio dissolvido $(5,40 \pm 0,62 \mathrm{mg}$ $\left.\mathrm{L}^{-1}\right)$, temperatura $\left(23,75 \pm 1,24^{\circ} \mathrm{C}\right), \mathrm{pH}(8,36 \pm 0,23) \mathrm{e}$ condutividade da água $\left(13,37 \pm 1,14 \mu \mathrm{S} \mathrm{ms}^{-1}\right)$. Esses parâmetros não apresentaram variações acentuadas e mantiveram-se dentro dos níveis adequados para o desenvolvimento dos peixes, de acordo com as recomendações de CARDOZO (2000) e PIEDRAS et al. (2004). Na tabela 2 , encontram-se os valores médios de desempenho produtivo dos alevinos de jundiá, em função dos níveis de fitase na dieta $\left(\mathrm{FTU} \mathrm{kg}^{-1}\right)$. A análise de regressão polinomial para ganho de peso médio (GP) e a taxa de crescimento específico (TCE) dos alevinos mostraram efeito linear crescente $(\mathrm{P}<0,05)$ até o nível de $1.500 \mathrm{FTU} \mathrm{kg}^{-1}$ (Figura 1).

O aumento linear observado no GP e na TCE com o incremento dos níveis de fitase na dieta pode estar relacionado com os efeitos positivos da fitase sobre a digestibilidade protéica e a disponibilidade de minerais, favorecendo sua absorção intestinal. $\mathrm{O}$ mesmo foi observado por PORTZ \& LIEBERT (2004) 
Tabela 2 - Desempenho produtivo de alevinos de jundiá (Rhamdia quelen) alimentados com níveis crescentes de fitase na dieta durante 45 dias.

\begin{tabular}{|c|c|c|c|c|c|}
\hline \multirow{2}{*}{ Variáveis } & \multicolumn{4}{|c|}{ Fitase (FTU kg ${ }^{-1}$ de dieta) } & \multirow{2}{*}{$\mathrm{p}$} \\
\hline & 0 & 500 & 1000 & 1.500 & \\
\hline Peso inicial (g) & $2,93 \pm 0,56$ & $2,92 \pm 0,61$ & $3,03 \pm 0,66$ & $2,81 \pm 0,53$ & - \\
\hline Peso final (g) & $\begin{array}{l}4,17 \pm 1,19 \\
15,62 \pm 3,19\end{array}$ & $\begin{array}{l}4,45 \pm 1,50 \\
15,88 \pm 3,68\end{array}$ & $\begin{array}{l}4,58 \pm 1,60 \\
16,76 \pm 4,63\end{array}$ & $\begin{array}{l}4,55 \pm 1,25 \\
16,63 \pm 4,12\end{array}$ & 0,436 \\
\hline $\mathrm{GP}(\mathrm{g})^{1}$ & $\begin{array}{l}1,24 \pm 0,27 b \\
2,99 \pm 1,18\end{array}$ & $\begin{array}{l}1,51 \pm 0,13 \mathrm{ab} \\
3,25 \pm 1,11\end{array}$ & $\begin{array}{l}1,54 \pm 0,48 a b \\
4,19 \pm 1,65\end{array}$ & $\begin{array}{l}1,73 \pm 0,23 \mathrm{a} \\
4,10 \pm 1,57\end{array}$ & 0,036 \\
\hline $\mathrm{CP}(\mathrm{cm})$ & $\begin{array}{l}6,46 \pm 0,64 \\
9,73 \pm 0,69\end{array}$ & $\begin{array}{l}6,52 \pm 0,72 \\
9,74 \pm 0,69\end{array}$ & $\begin{array}{l}6,58 \pm 0,76 \\
9,85 \pm 0,81\end{array}$ & $\begin{array}{l}6,64 \pm 0,65 \\
9,93 \pm 0,88\end{array}$ & 0,610 \\
\hline S (\%) & $\begin{array}{l}100 \\
100\end{array}$ & $\begin{array}{l}100 \\
100\end{array}$ & $\begin{array}{l}100 \\
100\end{array}$ & $\begin{array}{l}100 \\
100\end{array}$ & - \\
\hline $\operatorname{TCE}(\%)^{2}$ & $\begin{array}{l}0,78 \pm 0,12 b \\
0,49 \pm 0,18\end{array}$ & $\begin{array}{l}0,92 \pm 0,06 \mathrm{ab} \\
0,52 \pm 0,16\end{array}$ & $\begin{array}{l}0,89 \pm 0,19 a b \\
0,66 \pm 0,22\end{array}$ & $\begin{array}{l}1,07 \pm 0,11 \mathrm{a} \\
0,66 \pm 0,21\end{array}$ & 0,014 \\
\hline $\mathrm{FC}$ & $\begin{array}{l}0,76 \pm 0,04 \\
0,83 \pm 0,04\end{array}$ & $\begin{array}{l}0,78 \pm 0,12 \\
0,83 \pm 0,05\end{array}$ & $\begin{array}{l}0,77 \pm 0,04 \\
0,85 \pm 0,05\end{array}$ & $\begin{array}{l}0,78 \pm 0,04 \\
0,85 \pm 0,11\end{array}$ & 0,606 \\
\hline RC (\%) & $87,71 \pm 2,76$ & $88,23 \pm 1,87$ & $87,53 \pm 2,70$ & $89,52 \pm 2,32$ & 0,316 \\
\hline
\end{tabular}

Ganho de peso (GP), comprimento padrão (CP), sobrevivência (S), taxa de crescimento específico (TCE), fator de condição (FC) e rendimento de carcaça $(\mathrm{RC})$.

${ }^{1}$ Efeito linear $(\mathrm{P}<0,05) \mathrm{Y}=1,1329+0,1511 \mathrm{X}, \mathrm{r}^{2}=0,27$.

${ }^{2}$ Efeito linear $(\mathrm{P}<0,05) \mathrm{Y}=0,07102+0,083 \mathrm{X}, \mathrm{r}^{2}=0,35$.

Letras distintas na mesma linha indicam diferença estatística $(\mathrm{P}<0,05)$.

$\mathrm{p}=$ nível de significância.

para juvenis de tilápia do Nilo (Oreochromis niloticus) até o nível de 2.000FTU kg-1. Esses autores observaram aumento na TCE, no fator de condição e na taxa de eficiência protéica. No entanto, para tilápia do Nilo, FURUYA et al. (2001) observaram um melhor GP com níveis estimados de $890 \mathrm{FTU} \mathrm{\textrm {kg } ^ { - 1 }}$. Os resultados do presente experimento diferem dos observados por HUGUES \& SOARES (1998), que avaliaram a suplementação de diferentes níveis de fitase $(0,800$, 1.300 e $2.400 \mathrm{FTU} \mathrm{kg}^{-1}$ dieta) e fósforo inorgânico $\left(\mathrm{K}_{2} \mathrm{PO}_{4}\right)$, não encontrando efeito dos níveis de fitase sobre o ganho de peso entre os tratamentos para o striped bass (Morone saxatilis). As taxas de crescimento específico (TCE) aqui encontradas diferem dos resultados obtidos por COLDEBELLA \& RADÜNZ NETO (2002). Esses autores utilizaram dieta à base de levedura e farelo de soja para alevinos de jundiá com peso inicial médio de $4 \mathrm{~g}$, obtendo TCE de $2,98 \%$ ao dia. Além disso, utilizaram uma baixa densidade de peixes por unidade experimental (20 alevinos $280 \mathrm{~L}^{-1}$ de água), o que possivelmente tenha levado a um melhor desempenho.
O comprimento padrão $(\mathrm{CP})$ dos alevinos de jundiá teve um aumento numérico à medida que aumentaram os níveis de fitase na dieta, semelhantemente ao ganho de peso, porém não demonstrando diferença à regressão $(\mathrm{P}>0,05)$. A suplementação de fitase na dieta no presente experimento não interferiu na taxa de sobrevivência (S) dos alevinos, o que também foi observado por FURUYA et al. (2001) para tilápia do Nilo e POR VIELMA et al. (2000) para truta arco-íris (Oncorhynchus mykiss).

Não houve diferença $(\mathrm{P}>0,05)$ entre os valores de rendimento médio (RC) de carcaça entre tratamentos, tendo valor médio de $88,24 \%$. Este valor foi superior ao observado por MELO et al. (2002), na avaliação de diferentes fontes lipídicas para juvenis de jundiá com peso médio de $21,58 \mathrm{~g}$, trabalho em que obtiveram rendimento médio de $82,42 \%$. Foi também superior ao obtido por LAZZARI et al. (2006), que, avaliando diferentes fontes protéicas para juvenis de jundiá, obtiveram rendimento máximo de $81,9 \%$. 


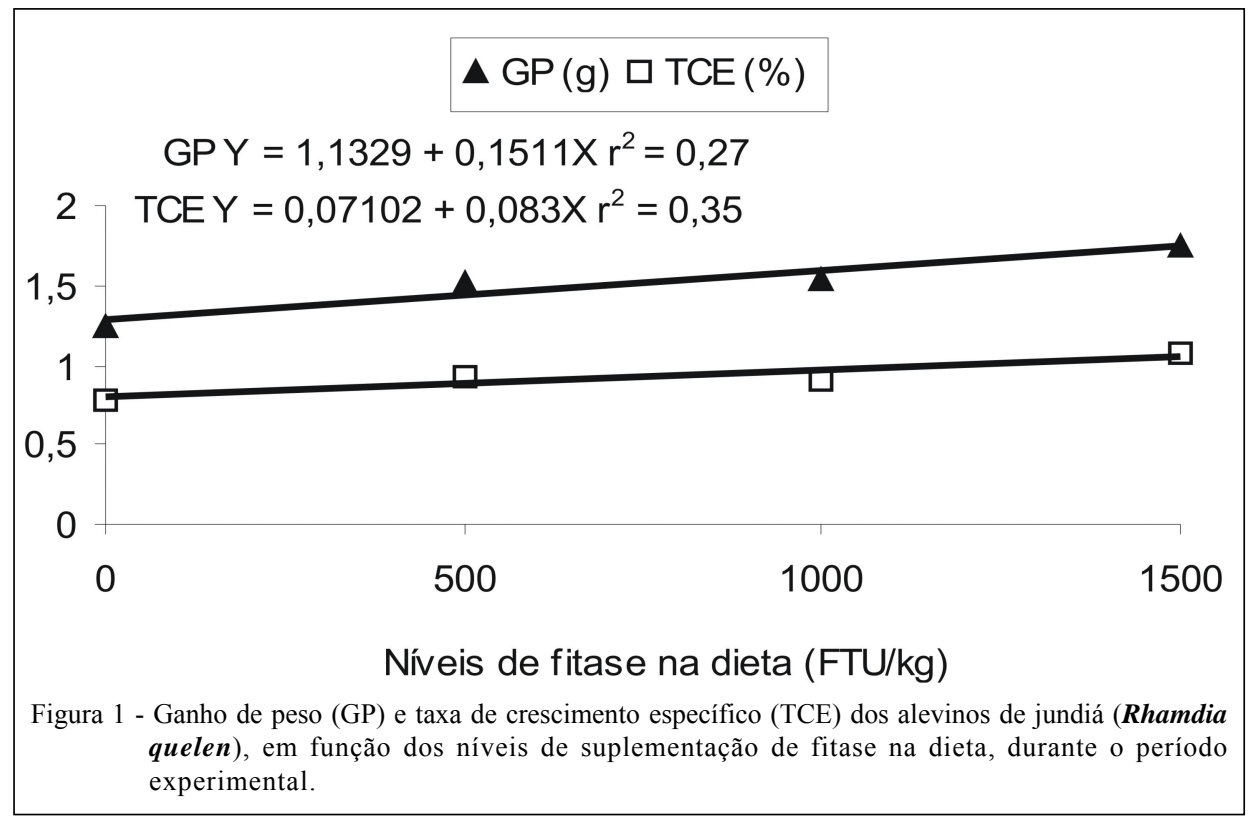

Os resultados das análises químicas das carcaças dos alevinos de jundiá foram submetidos à análise de variância e regressão polinomial, sendo apresentados na tabela 3. Os resultados da análise de regressão demonstraram que houve um decréscimo linear no extrato etéreo depositado na carcaça à medida que aumentaram os níveis de fitase na dieta $(\mathrm{Y}=14,1544$ $\left.-0,8353 \mathrm{X} ; \mathrm{r}^{2}=0,76\right)$. Este resultado se assemelha ao obtido por EYA \& LOVELL (1997), que, avaliando diferentes níveis de P disponível para o catfish de canal (Ictalurus punctatus), constataram que à medida que aumentavam os níveis de fósforo disponível na dieta, diminuía a deposição da gordura visceral e da gordura muscular. Isso evidenciaria que teria provavelmente ocorrido aumento na disponibilidade no $\mathrm{P}$ dietético. Este resultado difere dos obtidos por VIELMA et al. (2000), segundo os quais a adição de 1.000FTU kg-1 de dieta não afetou o extrato etéreo corporal de trutas arco-íris (O. mykiss). Discorda também dos resultados obtido por OLIVA-TELES et al. (1998), trabalho em que a suplementação de 1.000 e $2.000 \mathrm{FTU} \mathrm{kg}^{-1}$ na dieta de juvenis de seabass (Dicentrarchus labrax) não resultou diferença significativa no extrato etéreo corporal. Possivelmente, o estágio de desenvolvimento dos alevinos, no presente estudo, não possibilite a deposição de gordura na carcaça, já que a energia disponibilizada pela fitase pode ter sido gasta no metabolismo de formação dos tecidos estruturais. $\mathrm{Ou}$ seja, o aumento no ganho de peso foi devido à formação de outros tecidos, exceto a gordura na carcaça. $\mathrm{O}$ excesso de gordura na carcaça é, atualmente, uma característica indesejável, devendo manter-se em nível que não afete as características organolépticas da carne e auxilie na manutenção da sua qualidade durante o período de congelamento (MEURER et al., 2002).

Tabela 3 - Composição química das carcaças de alevinos de jundiá (Rhamdia quelen) em função dos níveis de suplementação de fitase na dieta.

\begin{tabular}{|c|c|c|c|c|c|}
\hline \multirow{2}{*}{ Variáveis (\%) } & \multicolumn{4}{|c|}{ Fitase (FTU kg ${ }^{-1}$ de dieta) } & \multirow{2}{*}{$\mathrm{p}$} \\
\hline & 0 & 500 & 1000 & 1500 & \\
\hline Proteína bruta & $68,58 \pm 0,08$ & $73,23 \pm 1,26$ & $71,34 \pm 2,58$ & $72,03 \pm 0,21$ & 0,166 \\
\hline Extrato etéreo $^{1}$ & $13,54 \pm 0,02 \mathrm{a}$ & $11,80 \pm 0,10 \mathrm{c}$ & $12,32 \pm 0,26 b$ & $10,59 \pm 0,10 \mathrm{~d}$ & 0,000 \\
\hline Cinzas & $14,57 \pm 0,57$ & $14,34 \pm 0,07$ & $15,38 \pm 0,10$ & $14,71 \pm 0,29$ & 0,272 \\
\hline Umidade & $78,74 \pm 0,84$ & $80,40 \pm 0,43$ & $78,41 \pm 0,89$ & $79,57 \pm 0,37$ & 0,856 \\
\hline
\end{tabular}

Médias obtidas a partir de 3 amostras $(n=3)$.

${ }^{1}$ Efeito linear $(\mathrm{P}<0,05) \mathrm{Y}=14,1544-0,8353 \mathrm{X}, \mathrm{r}^{2}=0,76$.

Letras distintas na mesma linha indicam diferença estatística $(\mathrm{P}<0,05)$.

$\mathrm{p}=$ nível de significância. 
As variáveis proteína bruta, umidade e cinzas não demonstraram efeito $(\mathrm{P}>0,05)$ dos níveis de fitase. Estes resultados concordam com VIELMA et al. (2000), que não observaram efeito sobre as cinzas, à proteína bruta e a umidade à adição de $1.000 \mathrm{FTU} \mathrm{kg}^{-1}$ na dieta à base de farelo de soja para truta arco-íris. Concordam também com os resultados obtidos por FORSTER et al. (1999), que, avaliando a adição de diferentes níveis de fitase para truta arco-íris $(0,500$, 1.500 e $4.500 \mathrm{FTU} \mathrm{kg}^{-1}$ ), em dieta à base de farelo de canola, não observaram diferença na umidade, nas cinzas, na proteína bruta, como também no extrato etéreo corporal. Valores semelhantes aos do presente experimento foram encontrados por MELO et al. (2002) com relação à umidade $(76,78 \%)$, à proteína bruta $(62,14 \%)$, ao extrato etéreo $(10,89 \%)$ e às cinzas $(13,73 \%)$ da carcaça de alevinos de jundiá alimentados com diferentes fontes lipídicas.

\section{CONCLUSÃO}

Níveis crescentes de fitase até $1.500 \mathrm{FTU} \mathrm{kg} \mathrm{kg}^{-1}$ na dieta aumentam o ganho de peso e a taxa de crescimento específico e reduzem linearmente o extrato etéreo na carcaça de alevinos de jundiá.

\section{AGRADECIMENTOS}

À Coordenação de Aperfeiçoamento de Pessoal de Ensino Superior (CAPES), pela bolsa de estudos ao primeiro autor, e à empresa BASF S.A., pela doação da enzima fitase.

\section{REFERÊNCIAS}

ASSOCIATION OF OFFICIAL ANALYTICAL CHEMISTS AOAC. Official methods of analysis. 15.ed. Washington DC., 1990. 1141p.

CARDOZO, L.B. Estudo da biometria, composição corporal e composição da carcaça do jundiá (Rhamdia sp.). 2000. 65f. Dissertação (Mestrado em Zootecnia) - Faculdade de Agronomia Eliseu Maciel, Universidade Federal de Pelotas.

CASEY, A.; WALSH, G. Identification and characterization of a phytase of potential commercial interest. Journal of Biotechnology, v.110, p.313-322, 2004.

CHENG, Z.J.; HARDY, R.W. Effect of microbial phytase on apparent nutrient digestibility of barley, canola meal, wheat and wheat middlings, measured in vivo using rainbow trout (Oncorhynchus mykiss). Aquaculture Nutrition, v.8, p.271277, 2002.

COLDEBELLA, J.I.; RADÜNZ NETO, J. Farelo de soja na alimentação de alevinos de jundiá (Rhamdia quelen). Ciência Rural, v.32, n.3, p.499-503, 2002.

DEBNATH, D. et al. Effect of dietary microbial phytase supplementation on growth and nutrient digestibility of Pangasius pangasius (Hamilton) fingerlings. Aquaculture Research, v.36, p.180-187, 2005.
EYA, J.C.; LOVELL, R.T. Available phosphorus requirements channel catfish (Ictalurus punctatus) diets in ponds of foodsize fed practical. Aquaculture, v.154, p.283-291, 1997.

FORSTER, I. et al. Potential for dietary phytase to improve the nutritive value of canola protein concentrate and decrease phosphorus output in rainbow trout (Oncorhynchus mykiss) held in 118C fresh water. Aquaculture, v.179, p.109-125, 1999 .

FRANCIS, G. et al. Antinutricional factores present in plantderived alternate fish feed ingredients and their effects in fish. Aquaculture, v.199, p.197-227, 2001.

FURUYA, W.M. et al. Fitase na alimentação da tilápia do Nilo (Oreochromis niloticus). Desempenho e digestibilidade. Revista Brasileira de Zootecnia, v.30, n.1, n.3, p.924-929, 2001.

HUGHES, K.P., SOARES JR, J.H. Efficacy of phytase on phosphorus utilization in practical diets fed to striped bass Morone saxatilis. Aquaculture Nutrition, v.4, p.133-140, 1998.

LAZZARI, R. et al. Diferentes fontes protéicas para a alimentação do jundiá (Rhamdia quelen). Ciência Rural, v.36, n.1, p.240-246, 2006.

MELO, J.F.B. et al. Desenvolvimento e composição corporal de alevinos de jundiá (Rhamdia quelen) alimentados com dietas contendo diferentes fontes de lipídios. Ciência Rural, v.32, n.2, p.323-327, 2002

MEURER, F. et al. Lipídeos na alimentação de alevinos revertidos de tilápia do Nilo (Oreochromis niloticus, L.). Revista Brasileira de Zootecnia, v.31, n.2, p.566-573, 2002.

OLIVA-TELES, A. et al. Utilisation of diets supplemented with microbial phytase by seabass (Dicentrarchus labrax) juveniles. Aquatic Living Resources, v.11, n.4, p.255-259, 1998.

OVERTURF, K. et al. Mineral availability from barley low phytic acid grains in rainbow trout (Oncorhynchus mykiss) diets. Aquaculture Nutrition, v.9, p.239-246, 2003.

PADUA, D.M.C. et al. Morfometria de hepatócitos de pacu, Piaractus mesopotamicus, submetidos à dietas com níveis crescentes de levedura de álcool, Saccharomyces cerevisiae. Ars Veterinária, v.16, n.1, p.1-8, 2000.

PIEDRAS, S.R.N. et al. Crescimento de juvenis de Jundiá (Rhamdia quelen), de acordo com a temperatura da água. Boletim do Instituto de Pesca, v.30, n.2, p.177-182, 2004.

PIZZOLANTE, C.C. et al. Níveis de fitase e de cálcio e desempenho de frangos de corte. Ciência Agrotecnica, v.26, n.2, p.418-425, 2002.

PORTZ, L.; LIEBERT, F. Growth, nutrient utilization and parameters of mineral metabolism in Nile tilapia Oreochromis niloticus (Linnaeus, 1758) fed plant-based diets with graded levels of microbial phytase. Jornal Animal Physiology and Animal Nutrition, v.88, p.311-320, 2004.

SAJJADI, M.; CARTER, C.G. Effect of phytic acid and phytase on feed intake, growth, digestibility and trypsin activity in 
Atlantic salmon (Salmo salar, L.). Aquaculture Nutrition, v.10, p.135-142, 2004.

SALES, J. et al. Dietary phosphorus leaching and apparent phosphorus digestibility from different inorganic phosphorus sources for South African abalone (Haliotis midae L.). Aquaculture Nutrition, v.9, p.169-174, 2003.

SOUZA, S.L. et al. Crescimento e sobrevivência do catfish de canal (Ictalurus punctatus) e jundiá (Rhamdia sp.) no outonoinverno do Rio Grande do Sul. Ciência Rural, v.35, n.4, p.891-896, 2005.
VAN WEERD, J.H. et al. Balance trials with African catfish Clarias gariepinus fed phytase-treated soybean meal-based diets. Aquaculture Nutrition, v.5, p.135-142, 1999.

VIELMA, J. et al. Influence of dietary soy and phytase levels on performance and body composition of large rainbow trout (Oncorhynchus mykiss) and algal availability of phosphorus load. Aquaculture, v.183, p.349-362, 2000.

VIELMA, J. et al. Top-spraying soybean meal-based diets with phytase improves protein and mineral digestibilities but not lysine utilization in rainbow trout, Oncorhynchus mykiss (Walbaum). Aquaculture Research, v.35, p.955-964, 2004. 